\title{
Thermochemistry of heteroatomic compounds: analysis and calculation of thermodynamic functions of amino acids and some peptides of different space structure
}

\author{
Vitaly Vitalevich Ovchinnikov
}

Department of General Chemistry and Ecology, Tupolev Kazan National Researching Technical University, St-K.Marks 10, 420111 Kazan, Tatarstan, Russia

\section{Email address:}

chem_vvo@mail.ru (V. V. Ovchinnikov)

\section{To cite this article:}

Vitaly Vitalevich Ovchinnikov. Thermochemistry of Heteroatomic Compounds: Analysis and Calculation of Thermodynamic Functions of Amino Acids and Some Peptides of Different Space Structure, American Journal of Physical Chemistry. Vol. 2, No. 1, 2013, pp. 8-15. doi: 10.11648/j.ajpc.20130201.12

\begin{abstract}
The values of free energies, the heats of combustion and formation in condensed and gaseous phases over 30 amino acids of different structure were analyzed. Entropies and heat capacities in standard conditions were considered too. Twenty one equations of such type as $\Delta \mathrm{Yo}_{\mathrm{o}}=\mathrm{i} \pm \mathrm{f}(\mathrm{N}-\mathrm{g})+\Sigma(\mathrm{hc}) \mathrm{j}$, in which $\Delta \mathrm{Yo}_{\mathrm{o}}$ is thermodynamic function or heat capacity, $\mathrm{i}$ and $\mathrm{f}$ are stoichiometric coefficiens, $\Sigma(\mathrm{hc}) \mathrm{j}$ are the sums of the number (j) of the heat corrections for the mentioned thermodynamic magnitudes, $\mathrm{N}$ is the number of valence electrons, from which a number of lone electron pairs ( $\mathrm{g}$ ) is excepted for. The obtained equations were used for the calculations of a new such parameters for four phosphorylated amino acids, two enkephalines and two human peptides of low molecular weights.
\end{abstract}

Keywords: Amino Acid, Free Energy of Combustion, Free Energy of Formation, Heat of Combustion Heat of Formation, Entropy, Heat Capacity, Enkephalines, Peptides

\section{Introduction}

The combustion process of heteroatomic compounds in the condensed state corresponds to equation (1) in general

$$
\begin{aligned}
& C_{a} \mathrm{H}_{b} \mathrm{~N}_{c} \mathrm{O}_{d} \mathrm{~S}_{e} \text { (cond) } \\
& +\left(\frac{4 a+b-2 d+6 e}{4}\right) \\
& \mathrm{O}_{2}(\text { gas }) \dot{a} a \mathrm{CO}_{2} \text { (gas) } \\
& +\left(\frac{b-6 e}{2}\right) \mathrm{H}_{2} \mathrm{O} \text { (liq) } \\
& +\left(\frac{c}{2}\right) \mathrm{N}_{2}(\text { gas }) \\
& +e\left[\mathrm{H}_{2} \mathrm{SO}_{4}\left(115 \mathrm{H}_{2} \mathrm{O}\right)\right]+\mathrm{D}_{c} Y^{o}
\end{aligned}
$$

in which a, b, c, d, e are stoichiometric coefficients and $\Delta$ Yo is a change of functions: free energy $(\mathrm{G})$, enthalpy $(\mathrm{H})$, entropy $(\mathrm{S})$ or heat capacity $(\mathrm{Cp})$ at the standard conditions.

According to the first law of thermodynamics the $\Delta Y_{0}$ value could be characterize by the equation (2), in which $\Delta \mathrm{fYo}$ are the correspondingly formation functions, ni and nj are stoichiometric coefficients also.

$$
\Delta_{\mathrm{c}, \mathrm{f}, \mathrm{s}} Y^{\circ}=\boldsymbol{\Sigma} n_{\mathrm{i}} \Delta_{\mathrm{f}} Y_{\text {products }}^{\circ}-\boldsymbol{\Sigma} n_{\mathrm{j}} \Delta_{\mathrm{f}} Y_{\text {reactants }}^{\mathrm{O}}
$$

Almost a century ago Kharasch and Sher have shown [1] that the heat of combustion of different organic compounds depends on the number of valence electrons. We followed to their base positions and showed also [2-4], that any function $\left(\Delta Y^{0}\right)$ or thermal parameter $(C p)$ of organic or bioorganic compounds of the Periodic Table of D.I. Mendeleev can be characterized within the limits of the one-factorial correlation analysis (Eq. 3) [5, 6].

$$
\Delta Y^{0}=i \pm f(N-g)+\boldsymbol{\Sigma}(h c)_{\mathrm{j}}
$$

We have shown also, using resulted in Metzler's monograph data $[7,8]$, that not only the heat of combustion and formation of amino acids but also the free energy of the same processes and entropy depend on the general number valence electrons $(\mathrm{N})$, from which the number lone electron pairs (g) (Eq. 1) is excluded or added. The last energetic term is the sum of heat corrections (hc), which necessary to introduce in equation (1) [1], when the researching compound has a distinguish fragments from other groups (j), for example acidic $>\mathrm{POOH},-\mathrm{COOH}, \mathrm{NH}-\mathrm{C}(\mathrm{O})$ groups or cycles of the different size.

All listed above gives a required basis to make the same 
analysis of the known values of thermodynamic functions $\left(\Delta G^{\mathrm{o}}, \Delta H^{\mathrm{o}}, S^{\mathrm{o}}\right)$ and heat capacity $(C p)$ of amino acids and to calculate these characteristics for other types of acids, phosphor-containing amino acids and peptides of low molecular weight.

\section{Results and Discussion}

\subsection{Amino Acids with Non Ionic Polar Lateral Chains}

According to the resulted in monography [9] classification, the structures of twenty one $\alpha$-amino acids, which are usually present in peptides and proteins, it is possible to divide into some groups. Amino acids, containing not ionic lateral chains, form the first of them: they are I - glycine (Gly), II - L-alanine (Ala), III - valine (Val), IV - creatine
(Cre), V - leucine (Leu), VI - L-threonine (Thr), VII - tyrosine (Tyr), VIII - asparagines (Asn), IX - glutamine (Gln), X - N-methyl-glycine (Megly), XI - proline (Pro), XII - DL-proline (DL-Pro), XIII - 1-hydroxy-proline (Hpro), XIV - N-formyl-dl-leucine (Form-leu), XV - isoleucine (Ile), XVI - DL-ornithine (Orn), XVII - phenylalanine (Phe), XVIII - L-serine (Ser), XIX - DL-serine (dl-Ser), XX - L-thriptophane (Trp) and XXI - N-carboxymethylglycine (N-carb-gly) in Table 1 . The values of the free energy of combustion $\left(\Delta_{\mathrm{c}} G^{\mathrm{O}}\right)$ and formation $\left(\Delta_{\mathrm{f}} G^{\mathrm{O}}\right)$ of some amino acids in the condensed phase are known in the literature (Table 1) [7]. The equations (4 and 5) were calculated with the use of all mentioned values of the free energies of amino acids (I-IX) (Table 1, columns 3 and 4)

Table 1. Thermodynamic functions $\left(\mathrm{kJ} \mathrm{mol}^{-1}, \mathrm{~J} \mathrm{~mol}^{-1} \mathrm{~K}^{-1}\right)$ of amino acids and peptides at $\mathrm{P} 101 \mathrm{kPa}$ and $298.15 \mathrm{~K}$; all compounds are in condensed state.

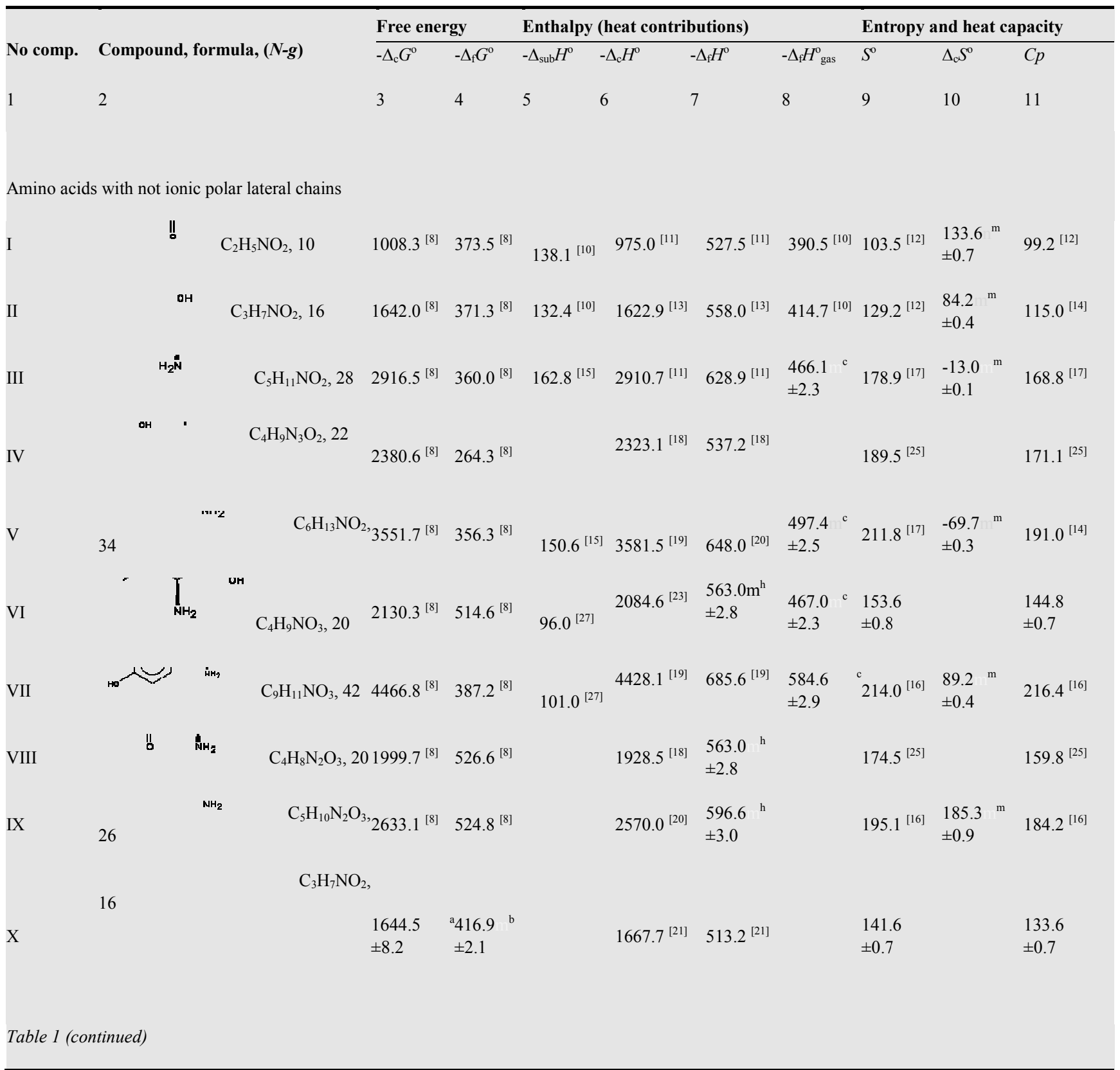




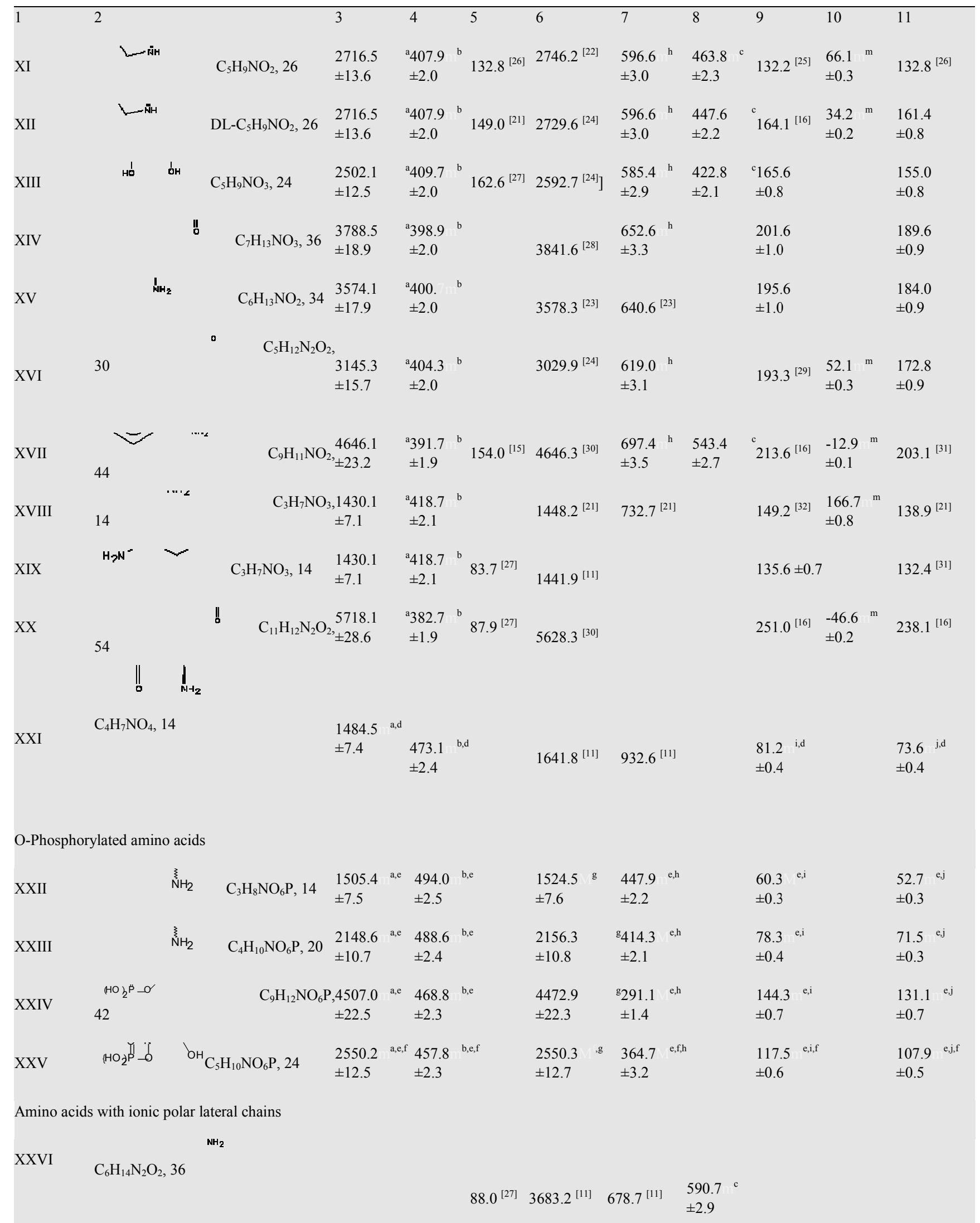




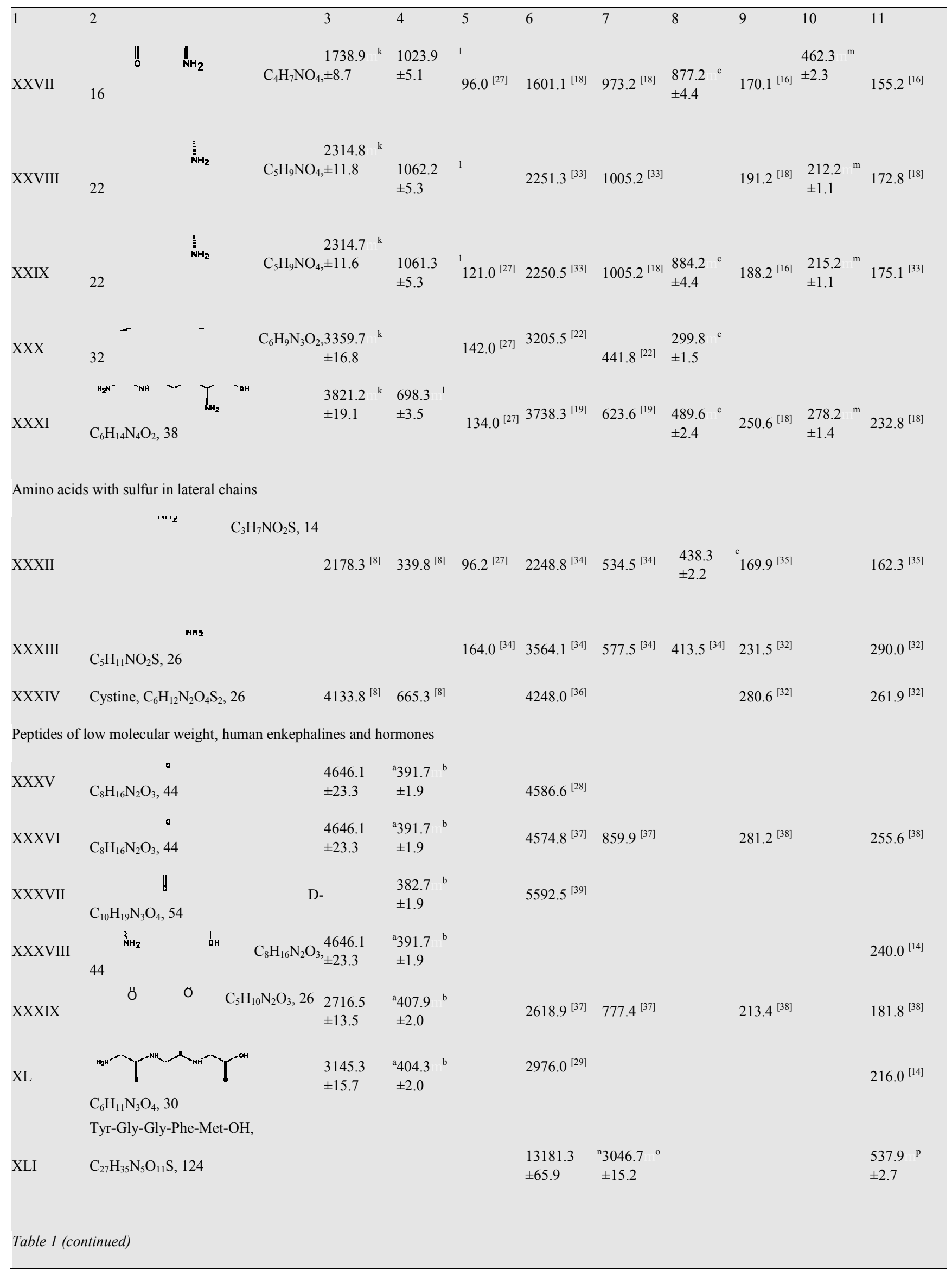




\begin{tabular}{|c|c|c|c|c|c|c|c|c|c|}
\hline 1 & 2 & 4 & 5 & 6 & 7 & 8 & 9 & 10 & 11 \\
\hline \multirow{2}{*}{ XLII } & Tyr-Gly-Gly-Phe-Leu-OH, & & & 14047.7 & ${ }^{\mathrm{n}} 2258.4^{\circ}$ & & & & $563.5^{\mathrm{p}}$ \\
\hline & $\mathrm{C}_{28} \mathrm{H}_{37} \mathrm{~N}_{5} \mathrm{O}_{11}, 132$ & & & \pm 70.2 & \pm 11.3 & & & & \pm 2.8 \\
\hline \multirow{2}{*}{ XLIII } & (-S)Cys-Tyr-Ile-Gln-Asn-Cys(S-)- & & & 22707.3 & ${ }^{\mathrm{n}} 4991.5^{\circ}$ & & & & $819.5^{\mathrm{p}}$ \\
\hline & Pro-Arg-GlyNH ${ }_{2}, \mathrm{C}_{43} \mathrm{H}_{67} \mathrm{~N}_{15} \mathrm{O}_{21} \mathrm{~S}_{2}, 212$ & & & \pm 113.5 & \pm 25.0 & & & & \pm 4.1 \\
\hline \multirow[b]{2}{*}{ XLIV } & (-S)Cys-Tyr-Ile-Gln-Asn-Cys(S-)- & & & 22382.4 & ${ }^{\mathrm{n}} 5316.4^{\mathrm{o}}$ & & & & $809.9^{p}$ \\
\hline & $\begin{array}{l}\text { Pro-Arg-GlyNH }{ }_{2}, \quad \mathrm{C}_{43} \mathrm{H}_{67} \mathrm{~N}_{12} \mathrm{O}_{21} \mathrm{~S}_{2}, \\
209\end{array}$ & & & \pm 111.9 & \pm 26.6 & & & & \pm 4.0 \\
\hline
\end{tabular}

${ }^{a}$ Calc. through Eq. (4); ${ }^{b}$ Calc. through Eq. (5); ${ }^{c}$ Calc. through Eq. (8); ${ }^{d}$ The contribution of COOH in -54.4 kJ mol ${ }^{-1}$ has been discounted [42]; ${ }^{e}$ The contributions of POOH in -75.4 $\mathrm{kJ} \mathrm{mol}^{-1}[42] ;{ }^{f} 5$-membered $\mathrm{N}$-cycle in $27.2 \mathrm{~kJ} \mathrm{~mol}^{-1}$ have been discounted [43]; ${ }^{g}$ Calc. through Eq. (6); ${ }^{h}$ Calc. through Eq. (7); ${ }^{i}$ Calc. through Eq. (11); ${ }^{j}$ Calc. through Eq. (12); ${ }^{k}$ Calc. through Eq. (18); ${ }^{l}$ Calc. through Eq. (19); ${ }^{m}$ Calc. through Eq. (10); ${ }^{n}$ Calc. through Eq. (23); ${ }^{\circ}$ Calc. through Eq. (1); $\Delta_{f} H^{o}$ for $\mathrm{CO}_{2}, \mathrm{H}_{2} \mathrm{O}$ and $\mathrm{H}_{2} \mathrm{SO}_{4}\left(115 \mathrm{H}_{2} \mathrm{O}\right)$ were taken from the book [44]; ${ }^{p}$ Calc. through Eq. (24).

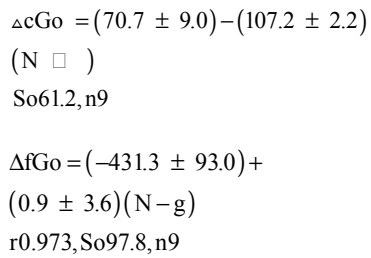

The heats of combustion $\left(\Delta_{\mathrm{c}} H^{\mathrm{O}}\right)$ magnitudes for compounds (I-XII, VIII-XXI) and formation $\left(\Delta_{\mathrm{f}} H^{\mathrm{O}}\right)$ values for (I-V, VII, X, XV) amino acids are known in the literature also (Table 1). Their thermochemical parameters depend directly from the number of valence electrons also (Eqs. 6 and 7)

$$
\begin{gathered}
\Delta_{\mathrm{c}} H^{\mathrm{o}}=(25.0 \pm 45.9)-(105.3 \pm 2.2)(N-g) \\
r 0.998, S_{\mathrm{o}} 61.2, n 20 \\
\Delta_{\mathrm{f}} H^{\mathrm{o}}=(-451.0 \pm 22.0)-(5.6 \pm 0.8)(N-g) \\
r 0.943, S_{\mathrm{o}} 23.5, n 8
\end{gathered}
$$

The heats of formation of amino acids (VI,VIII, IX, XIXIV, XVI, XVII) were calculated with the use of equation (7).

The heats of sublimation $\left(\Delta_{\mathrm{sub}} H^{\mathrm{o}}\right)$ of acids (I-III, V-VII, XI-XIII, XVII, XIX, XX) are known also. It has enabled to calculate the heats of formation of acids in a gas phase (Table 1 , column 8 ) with the use of equation (8)

$$
\Delta_{\mathrm{f}} H_{\text {gas. }}^{\mathrm{o}}=\Delta_{\mathrm{f}} H^{\mathrm{o}}+\Delta_{\text {sub }} H^{\mathrm{o}}
$$

The calculated $\Delta_{\mathrm{f}} H_{\text {gas }}^{\mathrm{o}}$ values of acids (I-III, V-VII, XIXIII, XVII,) are interrelated with the number of valence electrons as well as the heats of combustion in the condensed state (Eq. 9)

$$
\begin{gathered}
\Delta_{\mathrm{f}} H_{\text {gas. }}^{\mathrm{o}}=(-331.2 \pm 20.6)-(5.1 \pm 0.7)(N-g) \\
r 0.930, S_{\mathrm{o}} 22.9, n 10
\end{gathered}
$$

The entropy of combustion $\left(\Delta_{\mathrm{c}} S^{\circ}\right)$ of amino acids it is calculated in the works on thermodynamics of biochemical compounds rather seldom. We have calculated this thermodynamic function on the equation (2) for amino acids (I-III,
V, VII, IX, XI, XII, XVII, XVIII, XX) with the use of the standard entropy values of products and reactants, which are resulted in the equation (1) and ninth column in Table 1: for $\mathrm{CO}_{2}$ (gas) $S^{\circ}$ is equally 213.8 , for $\mathrm{H}_{2} \mathrm{O}$ (liq) $S^{\circ}$ is equally 70.1 , for $\mathrm{N}_{2}$ (gas) $S^{\circ}$ is equally 191.5 and for $\mathrm{O}_{2}$ (gas) $S^{\circ}$ is equally $205.1 \mathrm{~J} \mathrm{~mol}^{-1} \mathrm{~K}^{-1}$ [40]. The Eq. (2) receives the other form for entropy of combustion respectively, as it showed in Metzler's monograph [7] (equation 10):

$$
\Delta_{\mathrm{c}} S^{\mathrm{o}}=\boldsymbol{\Sigma} n_{\mathrm{iPf}} S_{\text {productsP }}^{\mathrm{o}}-\mathrm{P} \boldsymbol{\Sigma} n_{\mathrm{jPf}} S_{\text {reactants }}^{\mathrm{o}}
$$

The magnitudes of entropy combustion of amino acids with not ionic polar lateral chains represent in itself the positive and negative values that it follows from the definition of entropy as a function, describing a chaotic condition of thermodynamic system [7]. In the case of combustion of amino acid molecule in an oxygen atmosphere the greater number of particles are formed in comparison with an initial condition that leads to a positive value of entropy. The formation of negative values of the combustion entropy is comparable with negative magnitudes of free energy and the heat of combustion on the one hand, but from the other hand it can be connected with the uncertainties of experiments at the definition of standard entropies.

We analyzed known values in the literature of entropy for compounds (I-III, V, VII, IX, XII, XVI, XVII, XVIII, $\mathrm{XX}$ ) and the heat capacity for compounds (I-V, VII-IX, IX, $\mathrm{XI}, \mathrm{XVII}-\mathrm{XX})$. It has appeared, that they also as well as two previous functions, depend on the number of valence electrons (Eqs. 11 and 12 ).

$$
\begin{array}{r}
S^{\mathrm{o}}=(93.6 \pm 11.6)+(3.0 \pm 0.3)(N-g) \\
r 0.946, S_{\mathrm{o}} 14.5, n 11 \\
C p=(88.8 \pm 10.7)+(2.8 \pm 0.3)(N-g) \\
r \quad 0.923, S_{\mathrm{o}} 16.5, n 13
\end{array}
$$

The all received equations (2-8) were used for the calculation of free energies and the heat of combustion and formation, entropy (VI, X, XIII-XV, XIX, XXI) and heat capacity of amino acids (VI, X, XII-XVI, XXI) of this group, 
if they were not known until this time. In Table 1 are summed an experimental values, but all calculated now values are presented with the uncertainties $\pm 0.5 \%$.

\subsection{O-Phosphorylated Amino Acids}

Some proteins, such as casein and pepsine, contain the phosphorus allocated at their hydrolysis in the form of inorganic phosphate [41]. The most part of phosphorus is connected in proteins with some amino acids, such as Lserine and L-treonine, which were mentioned in previous part. The formation of such derivatives can be described by the general scheme (Eq. 13), in which phosphorus pentoxide serves as the water-taking away means

$$
\begin{aligned}
& \mathrm{HORCH}(\mathrm{NH} 2) \mathrm{COOH}+\mathrm{H}_{3} \mathrm{PO}_{4}+\mathrm{P}_{2} \mathrm{O}_{5} \rightarrow \\
& (\mathrm{HO})_{2} \mathrm{P}(\mathrm{O}) \mathrm{ORCH}\left(\mathrm{NH}_{2}\right) \mathrm{COOH}
\end{aligned}
$$

Free energies, the heats of combustion and formation in condensed and gaseous phases, standard entropies and the heat capacities of natural O-phospho-L-serine (XXII), Ophosphor-DL-treonine (XXIII) and synthetic O- phosphoL-tyrosine (XXIV) and O- phospho-L-hydroxyproline (XXV) (Table 1) have been calculated on the equation (4-7, 9-12). The contribution of hydrogen bond of $>\mathrm{POOH}$ group in $-75.3 \mathrm{~kJ} \mathrm{~mol}^{-1}$ [42] has been taken into account at the calculation of all mentioned above parameters.

\subsection{Amino Acids with Ionic Polar Lateral Chains}

This group consist six amino acids: XXVI - lysine (Lys), XXVII - D-aspartic acid (Asp), XXVIII - D-glutaminic acid (Glu), XXIX - L-glutaminic acid (Glu), XXX - histidine (His), XXXI - D-arginine hydrate(Arg). Basic amino acids (Lys, Arg and His) can carry the positive charge and form a $\mathrm{H}$-bonds because they have nitrogen-containing lateral groups $\left(\mathrm{H}_{2} \mathrm{~N}, \mathrm{H}_{2} \mathrm{~N}-\mathrm{C}=\mathrm{NH}\right.$ and imidazolic ring). Three amino acids (Asp, Glu and Thr from the first group) have the places in proteins often and carry a non-ionic groups. These bio-compounds are rather polarly to be on the surface of peptide or form H-bonds with the polar groups of other amino acids [9].

The heats of sublimation, combustion, formation in condensed and gaseous phases present in the literature also as an entropies and heats of capacity. Therefore the equations (14-17) were deduced for this group of amino acids, however the equation (16) has not significance practically.

$$
\begin{gathered}
\Delta_{\mathrm{c}} H^{\mathrm{o}}=(-57.3 \pm 81.0)-(98.7 \pm 2.8)(N-g) r 0.998, S_{\mathrm{o}} 55.8, \\
n 6(\text { compounds XXVI-XXXI) } \\
\Delta_{\mathrm{f}} H^{\mathrm{o}}=(-1355 \pm 102)+(18.6 \pm 3.6)(N-g) r 0.947, S_{\mathrm{o}} 70.2, \\
n 5(\text { compounds XXVI-XXIX, XXXI) }(15) \\
S^{\mathrm{o}}=(194.6 \pm 52.3)+(1.9 \pm 2.0)(N-g) r 0.548, S_{\mathrm{o}} 31.3, \\
n 4(\text { compounds XXVII-XXIX, XXXI) }(16) \\
C p=(96.4 \pm 3.1)+(3.5 \pm 0.1)(N-g) r 0.999, S_{\mathrm{o}} 2.0, \\
n 4(\text { compounds XXVII-XXIX, XXXI) }(17)
\end{gathered}
$$

As we have the known thermodynamic functions as the experimental $\Delta_{\mathrm{c}} H^{\circ}, \Delta_{\mathrm{f}} H^{\circ}, S^{o}$ and calculated through equation (10) $\Delta_{c} S^{o}$ values we have an opportunity to calculate free energy of combustion and formation $\left(\Delta_{\mathrm{c}} G^{0}\right.$ and $\left.\Delta_{\mathrm{f}} G^{0}\right)$ for amino acids (XXVI-XXXI) on famous Gibbs's equations (18 and 19); the calculated mentioned values have uncertainties $\pm 0.5 \%$ as a previously calculated in Table 1 magnitudes.

$$
\begin{gathered}
\Delta_{\mathrm{c}} G^{\mathrm{o}}=\Delta_{\mathrm{c}} H^{\mathrm{o}}-298.15 \cdot \Delta_{\mathrm{c}} S^{\mathrm{o}} \\
\Delta_{\mathrm{f}} G^{\mathrm{o}}=\Delta_{\mathrm{f}} H^{\mathrm{o}}-298.15 \cdot S^{\mathrm{o}}
\end{gathered}
$$

\subsection{Amino Acids with Sulfur in Lateral Chains}

Such amino acids as L-cysteine (XXXII), L-methionine (XXXIII) and cystine (XXXIV) form a special group in a general row of amino acids. They are connected with the globular proteins with the $\mathrm{H}$-bonds or ion-dipole interactions [9]. However this circumstance do not hinder to formation of not bad linear equations (20-22) between the $\Delta_{\mathrm{c}} H^{\circ}, S^{\circ}$ and $C p$ functions and the number of they valence electrons

$$
\begin{array}{r}
\Delta_{\mathrm{c}} H^{\mathrm{o}}=(-325.8 \pm 1091)-(137.3 \pm 48.0)(N-g) r 0.943, \\
S_{\mathrm{o}} 470.9, n 3(\text { compounds XXXII-XXXIII) }(20) \\
S^{\mathrm{o}}=(65.9 \pm 90.3)+(7.4 \pm 4.0)(N-g) r 0.881, \\
S_{\mathrm{o}} 39.0, n 3(\text { compounds XXVII-XXIX, XXXI) }(21) \\
C p=(29.7 \pm 46.1)+(9.5 \pm 2.0)(N-g) r 0.977, \\
S_{\mathrm{o}} 19.9, n 3 \text { (compounds XXVII-XXXI) }(22)
\end{array}
$$

\subsection{Peptides of Low Molecular Weight, Human Enkepha- lines and Hormones}

The different peptides take place at all alive cells and have a various biological actions. For example, they can be enzymes, genes, viruses or hormones to make a body of muscles, leather and hair. The peptides can contain a various quantity of the amino acid rests. The elementary peptides were studied by a thermochemical method: they are XXXV, XXXVI - N-DL-leucylglycines, XXXVII leucylglycilglycine, XXXVIII - DL-alanyl-dl-valine, XXXIX $\mathrm{N}$-dl-Alanylglycine and $\mathrm{XL}-\mathrm{N}$-(N-glycilglycil)glcine. These low molecular weight peptides form the equations (23 and 24) also as amino acids of the first, third and fourth types.

$$
\begin{gathered}
\Delta_{\mathrm{c}} H^{\mathrm{o}}=(218.5 \pm 87.6)-(108.3 \pm 2.1)(N-g) r 0.999, S_{\mathrm{o}} 49.0, \\
n 5(\text { compounds XXXV-XXXVII, XXXIX, XL) } \\
C p=(107.3 \pm 30.3)+(3.2 \pm 0.8)(N-g) r 0.941, S_{\mathrm{o}} 13.3 \\
n 4 \text { (compounds XXXVI, XXXVIII, XXXIX, XL) }
\end{gathered}
$$

With the use of these equations the heats of combustion and heats of capacities of methionine-enkephaline, eucineenkephaline, human varopressin and oxytocin (XLI XLIV) were calculated. 


\section{Conclusion}

The following conclusions could be done from summed here thermodynamic data. The values of free energies, the heats of combustion and formation in condensed and gaseous phases over 30 amino acids of different structure were analyzed. Entropies and heat capacities in standard conditions were considered too. Twenty one equations, in which the mentioned thermodynamic magnitudes are connected with the number of valence electrons were calculated and used for the calculations of a new such parameters for four phosphorylated amino acids and enkephalines human peptides of low molecular weights. Necessary to add, that these correlative comparisons will be useful for the future analysis of biochemical functions of the alive systems in the cell substances.

\section{References}

[1] Kharasch M.S. and Sher B., The electronic conception of valence and heats of combustion of organic compounds. J. Phys. Chem., 25: 625-658 (1925).

[2] Ovchinnikov V.V., Thermochemistry of Heteroatomic Compounds: Enthalpies of Combustion and Formation of Organic Derivatives of $\mathrm{P}, \mathrm{As}, \mathrm{Sb}$ and Bi. Doklady Phys. Chem., 411: 328-330 (2006).

[3] Ovchinnikov V.V., Thermochemistry of Heteroatomic Compounds: Calculation of Combustion and Formation Enthalpies of some Bioorganic Molecules of different Phenanthrenes Rows . Open J.Phys.Chem., 1: 1-5 (2011).

[4] Ovchinnikov V.V., Lapteva L.I., Thermochemistry of Heteroatomic Compounds: the Heats of Combustion and Formation of Clycoside and Adenosine Phosphates., Intern. J. Org. Chem., 1: 67-70 (2011).

[5] Ovchinnikov V.V., Thermochemistry of Heteroatomic Compounds: Enthalpy of Combustion and Formation of Organic Compounds of Groups I-VII Elements. Doklady Phys. Chem., 443: 69-72 (2012).

[6] Ovchinnikov V.V., Thermochemistry of Heteroatomic Compounds: Interdependence between of Some Thermochemical Parameters of the Different Classes Organic Nitro Compounds and a Number of Valence Electrons in their Molecules. American Chemical Science Journal, 3(1): 11-23 (2013).

[7] Metzler D.E., Biochemistry: The Chemical Reactions in Living Cells. Mir, Moscow, Vol.1, pp. 407 (1980).

[8] Metzler D.E., Metzler C.M., Sauke D.J., Biochemistry: The Chemical Reactions of Living Cells, Academic Press, 2nd Ed., pp. 1976 (2001).

[9] White A., Handler Ph., Smith E. L., Hill R.L., Lehman I.R., Principles of Biochemistry (Book 1). Moskow, Mir: 100109 (1981).

[10] Ngauv S.N., Sabbah R. and Laffitte M., Thermodynamique de composes azotes. III. Etude thermochimique de la glycine et de la 1- $\alpha$-alanine, Thermochim. Acta, 20: 371- 380 (1977).
[11] Vasilev V.P., Borodin V.A. and Kopnyshev S.B., Calculation of the standard enthalpies of combustion and formation of crystalline organic acids and complexones from the energy contributions of atomic groups., Russ. J. Phys. Chem. (Engl. Transl.), 65: 29- 32 (1991).

[12] Hutchens J.O., Cole, A.G. and Stout J.W. Heat capacities from 11 to $305 \mathrm{~K}$. and entropies of L-alanine and glycine, J. Am. Chem. Soc., 82: 4813-4815 (1960).

[13] Skoulika S. and Sabbah R., Thermodynamique de composes azotes. X. Etude thermochimique de laquelqes acides wamines, Thermochim. Acta, 61, 203-214 (1983).

[14] Badelin V.G., Kulikov O.V., Batagin V.S., Udzig E., Zielenkiewicz A., Zielenkiewicz W. and Krestov G.A., Physicochemical properties of peptides and their solutions, Thermochim. Acta, 169: 81-93(1990).

[15] Svec H.J. and Clyde D.D., Vapor pressures of some $\alpha$-amino acids, J. Chem. Eng. Data, 10: 151 (1965).

[16] Cole A.G., Hutchens J.O.and Stout J.W., Heat capacities from 11 to $305^{\circ} \mathrm{K}$. and entropies of L-phenylalanine, Lproline, L-tryptophane, and L-tyrosine. Some free energies of formation, J. Phys. Chem., 67: 1852-1855 (1963).

[17] Hutchens J.O., Cole A.G. and Stout J.W., Heat capacities from 11 to $305 \mathrm{oK}$, entropies and free energies of formation of L-valine, L-isoleucine, and L-leucine, J. Phys. Chem., 67: 1128-1130 (1963).

[18] Huffman H.M., Ellis E.L. and Fox S.W., Thermal data. VI. The heats of combustion and free energies of seven organic compounds containing nitrogen, J. Am. Chem. Soc., 58: 1728-1733 (1936).

[19] Huffman H.M., Fox S.W. and Ellis E.L., Thermal data. VII. The heats of combustion of seven amino acids. Huffman, H.M., Fox, S.W., and Ellis, E.L. Thermal data. VII. The heats of combustion of seven amino acids, J. Am. Chem. Soc., 59: 2144- 2149 (1937).

[20] Tsuzuki T. and Hunt H., Heats of combustion. VI. The heats of combustion of some amino acids, J. Phys. Chem., 61: 1668 (1957).

[21] Sabbah R. and Laffitte M., Thermochimique de composes azotes. IV. Etude thermochimique de la sarcosine et de la 1proline, Bull. Soc. Chim. Fr., 1: 50-52 , (1978).

[22] Vasilev V.P., Borodin, V.A. and Kopnyshev S.B., Standard enthalpies of formation of L-histidine and L-proline, Russ. J. Phys. Chem. (Engl. Transl.), 63: 891-892 (1989).

[23] Wu D., Zhu Y., Gao Z. and Qu S., Determination of combustion heat of some amino acids. Wuhan Daxue Xuebao Ziran Kexueban: 78-82 (1993).

[24] Ponomarev V.V. and Migarskaya L.B., Heats of combustion of some amino- acids, Russ. J. Phys. Chem. (Engl. Transl.), 34: 1182-1183 (1960).

[25] Huffman H.M. and Borsook H., Thermal data. I. The heat capacities, entropies and free energies of seven organic compounds containing nitrogen, J. Am. Chem. Soc., 54: 4297- 4301 (1932).

[26] Stephenson R.M. and Malanowski S., Handbook of the Thermodynamics of Organic Compounds, Elsevier: New York (1987). 
[27] Chickos J.S. and Acree W.E., Jr., Enthalpies of Sublimation of Organic and Organometallic Compounds 1910 - 2001, J.Phys.Chem.Ref. Data, (2): 537- 698 (2002).

[28] Wrede F., Uber die Bestimmung von Brennungswarten mittels der kalorimetrischen Bombe unter Benutzung des Platinwiders- tandsthermometers, Z. Phys. Chem. (Leipzig): 81-94 (1911).

[29] Huffman H.M. and Fox S.W., Thermal data. XIII. The heat capacities and entropies of creatine hydrate, DL- citrulline, DL-ornitine, L-proline and taurine, J. Am. Chem. Soc., 62: 3464-3465 (1940).

[30] Tsuzuki T., Harper D.O. and Hunt H., Heats of combustion. VII. The heats of combustion of some amino acids, J. Phys. Chem., 62: 1594-1595 (1958).

[31] Spinr H.J. and Wadsö I., Thermochemistry of solutions of biochemical model compounds. 4. The partial molar heat capacities of some $\alpha$ - amino acids, J.Chem.Eng. Data,10: 151 (1965).

[32] Hutchens J.O., Cjle A.G. and Stout J.W., Heat capacities from 11 to $305 \mathrm{~K}$, entropies, enthalpy, and free energy of formation of L-serine, J. Biol. Chem., 239: 4194- 4195 (1964).

[33] Sakiyama M. and Seki S., Enthalpies of combustion of organic compounds. II. L- and D-glutamic acid, Bull. Chem. Soc. Jpn., 48: 2203-2204 (1975).

[34] Sabbah R. and Minidakis C., Thermodynamique de substances soufree. II. Etude thermochimique de la l-cysteine et de la l-methionine, Thermochim. Acta, 43: 269-277(1981).
[35] Huffman H.M. and Ellis E.L., Thermal data. VII. The heat capacities, entropies and free energy of four organic compounds containing sulfur, J. Fm. Chem. Soc., 57: 46-48 (1935).

[36] Sunner S., Determination of combustion heats of organosulfur compounds, Svensk. Kim. Tidr., 58: 71-81 (1946).

[37] Huffman H.M., Thermal data. XV. The heats of combustion and free energies of some compounds containing the peptide bond, J. Phys. Chem., 46: 885- 889(1942).

[38] Huffman H.M., Thermal data. XIV. The heat capacities and entropies of some compounds having the peptide bond, J. Am. Chem. Soc., 63: 688-689 (1941).

[39] Fischer E. and Wrede F., Uber die Verbrennungswarme einiger organischer Verbindungen. Sitzungsber, Dtsch. Akad. Wiss. Berlin Kl. Math. Phys. Tech.: 687-715 (1904).

[40] Karapetyanz M. Kh. and Karapetyanz M.L., The basic thermodynamic constants of inorganic and organic substances, Moscow, Chemistry, 471pp. (1968).

[41] Greenstein J.P. and Winitz M., Chemistry of the amino acids, NY- London, John Wiley \& Sons, Inc., 821 pp. (1961).

[42] Gragerov I.P., Pogorelyi V.K. and Franchuk I.F, Hydrogen bond and rapid exchange, Kiev, Naukova Dumka, 215 pp. (1978).

[43] Benson S.W., Thermochemical kinetics Moscow, Mir, 308 pp. (1971).

[44] Cox J.D. and Pilcher G., Thermochemistry of Organic and Organometallic Compounds, Academic Press - London and New York, pp. 640 (1970). 